\title{
Determinants Of Efficient Networks: An Empirical Analysis
}

Andrew Ben Nyaboga, Ph.D., William Paterson University, USA

Muroki F. Mwaura, Ph.D., William Paterson University, USA

\begin{abstract}
Although management support and user involvement have been reported to be contributors of network success, vendor support may be one of the most determinants of network efficiency. The user of any system takes what has been given to him or her by vendors and is only perfected by habituation. The other factor that may determine the implementation of effective network is traffic measurement, which is achieved by measuring server performance, network performance and application performance.
\end{abstract}

Keywords: Computing Devices, Collection Of Equipments, Structural Properties, Organization Structure, Networks, Network Design

\section{INTRODUCTION AND LITERATURE REVIEW}

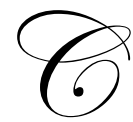

omputer networks or communication networks are a collection of computing devices that communicate by exchanging data and sharing resources without regard to geographical boundaries. Umar (1997) defines networks as "a collection of equipments, software modules and physical media viewed as one autonomous whole that interconnects two or more computers." The development and implementation of networks has been the main focus of organizational scholars for the last four decades or so. The evaluation of networks and their effectiveness is important for an effective organizational strategy and for the equitable distribution of available resources. In implementing an effective network, it is necessary to understand how networks work and the determining factors (O'Tooles, 1997). There are a myriad of factors which may affect the implementation and development of an effective network.

This study posits that the implementation of an effective network may depend on the structure of the organization. Structure is a component of formalization, centralization and complexity. The study investigates the relationships between these structural properties and the implementation of networks. The study tries to answer the following question: Which of these logical constructs, as defined by Sack et. al. (1999), will aid an organization in achieving its desired goals viz - an effective network. Deming (1986) has argued that an effective network must be evaluated on the impact it has to the end users. "By satisfying customers and maintaining a customer driven focus, the organization will presumably be effective, but also to other stakeholders, such as suppliers, stockholders, and employees, all who stand to benefit by reaping the rewards that accrue to a customer driven organization."

Network effectiveness is achieved if an organization is effective in implementing its strategies; therefore the effectiveness of networks must be evaluated as service delivery vehicles that must provide tangible and intangible benefits to the organization and the stakeholders. According to Milward and Provan (2001), the examination of the relationships between structure and the measures of activities is critical for understanding the importance and effectiveness of networks. Fichter (2001) has pointed out that for network design to be successful, it must do things that the user perceives to be valuable, i.e., increase of accuracy, relevancy, faster speed, and easy use. Some researchers have identified management support as one of the factors that may influence the development of a successful network (Phelps and Mok, 1999). A study by Camillus and Lederer (1985) shows that the effectiveness of end user computing can be measured by the availability and accessibility of networks. Their argument is based on logical access and physical access. One may have an access to networks, thus physical access but limited logical access to the data or information. Camillus and Lederer (1985) argue that satisfaction increases when end users 
have a greater degree of availability and accessibility of a computerized information system. Another study by Igbaria (1990) posits that if there is a lack of support from management and the availability of free access to computer resources, the end users of those resources lose interest in the system. Additionally, the accuracy and upto-date of information is necessary for networks to be considered effective. In another research by Milward and Provan (1995), they argue that research in networks and their performance involves organizational antecedents and their outcomes; therefore, effectiveness is measured at network level. In this research, effectiveness means that the end user is satisfied with all the factors that impact his or her ability to perform.

\section{PROBLEM: RESEARCH METHODOLOGY AND INSTRUMENTS USED}

This research attempts to identify factors that are related to the implementation of effective networks. If these factors are identified, then the network designer could be in a position to concentrate on those factors that will have a greater impact on network development and implementation. Figure 1 below includes major factors that may explicitly or implicitly affect the implementation of an effective network.

Figure. 1

\begin{tabular}{|c|c|c|}
\hline \multicolumn{3}{|c|}{ Possible Characteristics That May Affect The Implementation Of An Effective Network } \\
\hline $\begin{array}{c}\text { Organization } \\
\text { Structure Factors } \\
\end{array}$ & Efficiency Factors & Human Factors \\
\hline $\begin{array}{ll}- & \text { Complexity } \\
\text { - } & \text { Formalization } \\
\text { - } & \text { Centralization }\end{array}$ & $\begin{array}{ll}\text { - } & \text { Accuracy } \\
\text { - } & \text { Availability } \\
\text { - } & \text { Accessibility } \\
\text { - } & \text { Reliability } \\
\text { - } & \text { Timeliness } \\
\text { - } & \text { Consistency } \\
\text { - } & \text { Completeness } \\
\text { - } & \text { Currency } \\
\end{array}$ & $\begin{array}{ll}- & \text { Management Support } \\
\text { - } & \text { User Involvement } \\
\text { - } & \text { Vendor Support }\end{array}$ \\
\hline
\end{tabular}

In this section, structure, efficiency factor, and human factor qualities are discussed in detail, Including other related factors not included in Figure 1.

\section{HUMAN FACTORS}

The evaluation of networks by decision makers is necessary so that the limited resources can be allocated to a service delivery mechanism that may utilize the available resources effectively and efficiently. The implementators of networks have a duty of making sure that there is improved access and, at the same time, a reduction of costs. This can be achieved by training users of these networks in order to reduce response time. Additionally, the support of top management is needed to bring all the workers together for a common goal. While a network may benefit the organization where it is embedded, particularly the client it serves, it must become a viable interorganizational entity to survive (Milward, 2001). The need for top management support is crucial in determining the type of networks needed and at the same time, making sure the organization has a consensual validation and the ability of creating social capital. According to Cheney and Fuerst (1982), user involvement and user training may be important in implementing an effective network. The vendor support is a requisite for the maintenance of software and hardware as may be required by the organization.

\section{ORGANIZATIONAL STRUCTURE}

One other way of assessing network effectiveness is by evaluating the structure of an organization. Structure is a component of complexity, formalization and centralization. Complexity refers to the number of occupational specialists, the professional activity, and the professional training of employees (Robbins, 1990). It refers to unstructured decisions or non-routine functions. 
Formalization refers to when jobs within an organization are structured or routine. If work to be performed is formalized, it means that an employee has no say or discretion over what is to be done. It is a measure of standardization, where procedures on how to do some work are either written or not written, but well understood. Standardization or routine promotes coordination.

Centralization refers to the degree to which decision making is concentrated at a single point in the organizational hierarchy. Decentralization refers to low concentration in the organizational hierarchy.

In this study, we explain factors which have been applied in the literature for implementing information systems and use them in networks. Top management support and structure are assumed to be the most important factors in determining the implementation of any system, including networks. Measuring efficiency will be determined using dimensions of data quality as a measure of satisfaction.

\section{EFFICIENCY FACTORS}

A number of factors may affect the efficiency and the implementation of an effective network. Effectiveness means user satisfaction has been achieved. In this study, accuracy, timeliness, consistency, currency, relevancy, completeness and accessibility are the major factors which we shall use to measure the effectiveness of networks. If the information received from the network is not of quality, then what is the need? Dimensions of data quality will be used as a measure of effectiveness.

\section{ACCURACY}

Accuracy of a datum or data entity, attribute and value refers to closeness of some value " $V$ " to other value " $\mathrm{V}^{1}$ ". The value $\mathrm{V}^{1}$ is referred to as a standard of measure; which means that if $\mathrm{V}=\mathrm{V}^{1}$, then the datum is accurate. It is the degree of agreement between a particular value and an identified source which supplies values.

\section{TIMELINESS}

In the data creation process, timeliness is the difference between when data or a datum is due and when it is received. If data is there when it is needed, it is timely and satisfies the timeliness requirement.

\section{CONSISTENCY}

Data are said to be consistent with respect to a set of constraints. If they satisfy all constraints on the data model. Constraints may be on the same semantic entity or across semantic entities. Consistency does not imply correctness or accuracy but a degree to which required synchronization between two triples is achieved. If two triples are inconsistent, then one must be inaccurate.

\section{CURRENCY}

The degree to which a specific piece of data is up to date. It is up to date at time " $\mathrm{t}$ " if accurate at time " $\mathrm{t}$ ". It is out of date at time " $\mathrm{t}$ " if not accurate at time " $\mathrm{t}$ " and accurate at time " $\mathrm{t}-\mathrm{n}$ ".

\section{COMPLETENESS}

The degree to which values are present in the semantic items that require them. According to Redman (1992), completeness is the degree to which values are present in a data collection.

\section{RELEVANCY}

According to Bailey and Pearson (1983), relevancy refers to the degree of congruence between what is needed by the user to accomplish his or her objective and what is provided by the information products and services. 


\section{ACCESSIBILITY}

According to Culnan (1984), it refers to two things: terminal accessibility and informational accessibility. The availability of the terminal to the end users is important to achieve their objectives. Additionally, the availability of information is equally important. You may get physical access to networks but may not be able to get the information you need. Data may be present but not accessible to the user or those who want to use it.

\section{BRINGING IT TOGETHER: A MODEL OF EFFECTIVE NETWORKS}

The implementation of effective networks means that they should efficiently and effectively supply the required information for decision makers. This study argues that there is a relationship between effectiveness and efficiency and structural properties. Figure 2 below depicts the model of our study. We argue that there is a synergy brought by structural properties, concomitantly with the effectiveness of human factors that contribute to an effective network.

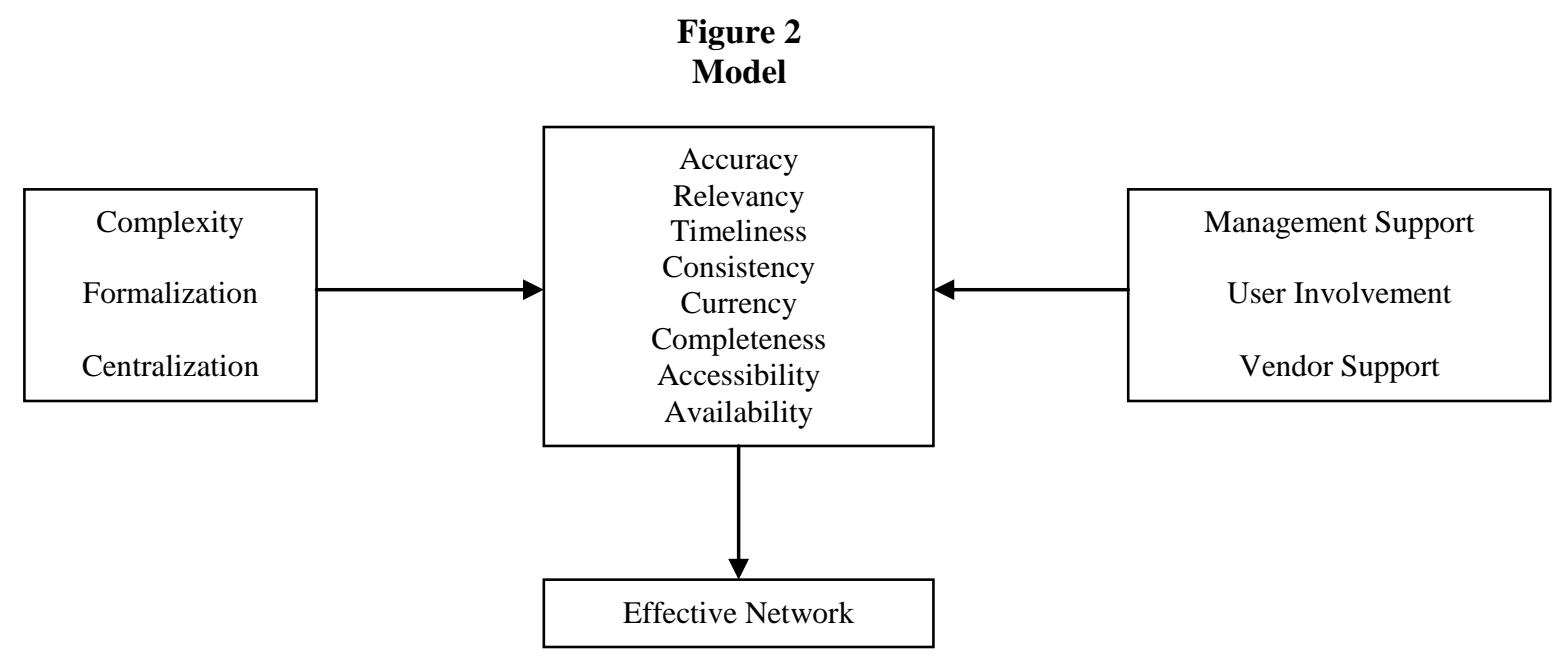

First, with regard to management support and user involvement, our study posits that top management support will have an impact on implementing effective networks. Additionally, this paper broaches further by arguing that vendor support will have an effect when implementing networks. Second, the dimensions of organizational structure will have an impact on the implementation process. According to Figure 2, formalization, complexity and centralization will dictate how effective the networks will be. The synergy of implementation factors accompanied by structure that is aligned with management support and user involvement will bring the desired outcome as measured by effectiveness variables, i.e., accuracy, reliability and currency interalia.

\section{PROCEDURES}

For this study, two questionnaires were developed from previous research. These instruments were psychometrically validated and therefore valid for this study.

One instrument was used to measure effectiveness with respect to data quality dimensions; the other to measure the dimensions of organizational structure, i.e., complexity, formalization and centralization. The measure of effectiveness is measured in terms of user information satisfaction. This instrument was developed by Pearson and Bailey (1983); and adapted for this study. The instrument has been modified and subsequently used by many researchers. 


\section{DEVELOPMENT OF SAMPLE POPULATION AND DATA COLLECTION}

This section describes how the sample population of this study was developed. Two procedures were adapted as personal reference to collect data. The first procedure was to contact randomly some organizations in the state of New Jersey and request the administrators to participate in the study. We contacted 80 organizations, but 36 of those contacted were willing to participate. The second procedure was to send two sets of questionnaires to the administrator of those organizations. The administrators were requested to answer questionnaire set "A" and distribute questionnaire set "B" to the supporting staff. All 72 questionnaires were returned in a usable form.

\section{DATA ANALYSIS AND RESULTS}

The data for this study was analyzed using SPSS Software Package. The study focused on correlations. As indicated in Table 1, rules and procedures followed as a measure of structure attracted the highest means (3.583) and the Standard Deviation of 0.9673. This higher means indicates that in most organizations that participated in the study, work is formalized (structured) in nature. Superior seeking advice from lower level staff is not encouraged because it attracted the lowest means of 2.5000 .

Table 1

Descriptive Statistics

\begin{tabular}{|l|c|c|}
\hline \multicolumn{1}{|c|}{ Variables } & Mean & Standard Deviation \\
\hline Express opinion & 2.8056 & 1.1647 \\
\hline Have a voice & 3.0278 & 0.9706 \\
\hline Make suggestions & 2.8889 & 1.0359 \\
\hline Speak my mind & 2.6944 & 1.0903 \\
\hline Supervisor seeks advice & 2.5000 & 1.1339 \\
\hline My job is defined & 2.6111 & 1.0764 \\
\hline I check with supervisor & 3.1389 & 1.1748 \\
\hline No influence & 3.2778 & 1.0586 \\
\hline Supervisor makes decisions & 3.4444 & 1.2058 \\
\hline Rules and procedures followed & 3.5833 & 0.9673 \\
\hline Do not play active role & 3.2222 & 1.1492 \\
\hline
\end{tabular}

As indicated in Table 2, relevancy and currency attracted the highest means of 3.9722 and 3.9444 respectively, meaning that the information received by the administrator was relevant and current.

In this study, however, there were no significant correlations between the measure of effectiveness factors and structure. This means structural properties of an organization do not determine network effectiveness.

The most interesting finding in this research is the high intercorrelation among the effectiveness factors. As indicated in Table 3, there were some intercorrelations between availability and accuracy (.760) and currency and relevancy (.708). The purpose of this study, however, was not to develop a detailed mechanism to evaluate networks, but to develop a simple model for evaluating the factors that must be considered when implementing networks. The intercorrelations which were observed must be considered separately in a different study.

However, networks may be assessed by the actual service they provide; e.g., providing ad hoc reports to different people at different areas eliminating the waste of organization resources. Our assumption is that network effectiveness must be measured by the end users (clients) who receive the network benefits. This can be measured in terms of improved access, cost reduction, utilization and response time. Although networks may support the clients, the seamless between management and the organizational client must coexist. Therefore, the service provided by networks is the most determinant factor of its effectiveness. 
Table 2

Descriptive Statistics

\begin{tabular}{|l|c|c|}
\hline \multicolumn{1}{|c|}{ Variables } & Mean & Standard Deviation \\
\hline Accurate & 3.6944 & 0.7491 \\
\hline Complete & 3.5833 & 0.9373 \\
\hline Accessible & 3.6944 & 1.0091 \\
\hline Consistency & 3.6389 & 0.9607 \\
\hline Currency & 3.9444 & 0.9241 \\
\hline Relevancy & 3.9722 & 0.9706 \\
\hline Management Involvement & 3.8333 & 1.0282 \\
\hline Reliable & 3.8056 & .08886 \\
\hline Available & 3.9444 & 1.0126 \\
\hline
\end{tabular}

Table 3

Correlations

\begin{tabular}{|l|c|c|c|c|c|c|c|c|c|c|}
\hline & Accurate & Timely & Reliable & Current & Complete & Consistent & Relevant & Accessible & Available & Mgt \\
Support
\end{tabular}

Correlation is significant at 0.05 level.

\section{CONCLUSIONS}

For this sample, there were no significant relationships between the logical constructs and network effectiveness factors. Our assumption is that in evaluating network effectiveness, there are many problems that are observed. First, the stakeholders' and vendors' interests are quite diverse. Second, the network serves different groups, e.g., the clients, management and the workers. To evaluate network effectiveness, all three network clients must be considered independently.

Although management support and user involvement have been reported to be contributors of network success, vendor support may be one of the most determinants of network efficiency. The user of any system takes what has been given to him or her by the vendors and is only perfected by habituation. The other factor that may determine the implementation of effective networks is traffic measurement, which is achieved by measuring server performance, network performance and application performance. With all these in mind, the most important stakeholder is the customer. Therefore, the best measures of implementing an effective network is the contribution they make to the customer of the organization and that customer will be satisfied if there is improved access, utilization responsiveness and a seamless quality. However, it is important to note that network efficiency can be judged by the service it provides to the clients who need them and not the way the organizations are structured.

\section{AUTHOR INFORMATION}

Dr. Andrew B. Nyaboga earned his Ph.D at Stevens Institute of Technology, Hoboken New Jersey in 2000.Currently he is an associate professor of Accounting and Law at William Paterson University in Wayne New Jersey and teaches courses in accounting and accounting Information System. His research interests are in technology management and knowledge management. His work has been published in numerous refereed journals. 
Dr. Muroki F. Mwaura earned his Ph.D at the University of Illinois Urbana -Champaign in 1994. Currently he is a professor of Accounting and Law at William Paterson University in Wayne New Jersey and teaches courses in accounting. His research interests are in Accounting in developing countries and knowledge management. His work has been published in numerous refereed journals.

\section{REFERENCES}

1. Bailey, James E. Development of Tool for Measuring and Analyzing Computer User Satisfaction. 1983.

2. Camillus, J.C., et. al. "Corporate Strategy and Design of Computerized Information Systems." Sloan Management Review. 1985.

3. Cheney, H., et. al. "Concepts, Theory and Techniques: Factors Affecting the Perceived Utilization of Computer-Based Decision Support System in the Oil Industry.” Decision Science. 1982.

4. Culnan, M.J. "The Dimensions of Accessibility to Online Information: Implications for Implementing Office Information Systems.” ACM Transactions on Office Information Systems. 1984.

5. $\quad$ Deming, W. Edward. Out of the Crisis. Cambridge MA. MIT. 1986.

6. $\quad$ Fichter, D. "Getting the Job Done: Designing Accessible Intranet Sites." (Wilson, Conn) V. 6, No. 3. 2001.

7. Igbaria, M. "End-User Computing Effectiveness: A Structural Equation Model." International Journal of Management Science. 1990.

8. Milward, B. H., et. al. "Do Networks Really Work: A Framework for Evaluating Public Sector Organizational Networks.” 2001, vol. 61, \#4.

9. Milward, B.H., et. al. "A Preliminary Theory of Network Effectiveness: A Comparative Study of Four Community Mental Health Systems." Administrative Science Quarterly, 1995 (40).

10. Phelps, R., et. al. "Managing the Risk of Intranet Implementation: An Empirical Study of User Satisfaction." The Association of Information Technology Trust. 1999.

11. Redman, T.C. Data Quality Management and Technology. Bantam Books. 1992.

12. $\quad$ Robbins, S.P. Organization Design, Structure Design and Application. $3^{\text {rd }}$ Edition. Prentice Hall. 1990.

13. Sack, I., et. al. Organizational Modeling for the $21^{\text {st }}$ Century. Prentice hall. 1999.

14. Toole, Laurence J. "Treating Networks Seriously: Practical and Research-Based Agendas in Public Administration." Public Administration Review. 57(1):45-52.

15. Umar, A. Distributed Computing: A Practical Synthesis. Prentice Hall. 1993. 
NOTES 